\title{
Effect of the Improved Pall Friction Damper on the Seismic Response of Steel Frames
}

\author{
Parviz Hosseini Sarjou \\ Department of Civil Engineering, \\ Higher Educational Complex of Saravan, Iran.
}

\author{
Naser Shabakhty \\ Department of Civil Engineering, Iran University of \\ Science and Technology, Tehran, Iran.
}

\begin{abstract}
Energy-absorbing dampers are used to reinforce structures which are vulnerable to earthquakes. This study evaluates the performance of Improved Pall Frictional Dampers (IPFD) which is a type of Pall Frictional Damper (PFD). For this purpose, this study compares the performances of steel frames with concentric steel bracing reinforced by IPFD and steel frames with concentric steel bracing with no damper. Frames with different stories and pans were modelled in sap2000 and exposed to accelerograms of earthquakes for non-linear time history analysis. Results of analysis were studied; parameters such as story displacement, base shear and absorbed energy were compared in steel frames with damper and without damper.
\end{abstract}

Keywords- pall; damper; energy absorption

\section{INTRODUCTION}

During an earthquake, a great deal of energy is applied to the structure. Different methods are used to confront this energy applied to the structure; these methods usually control damage to the structure. One of the conventional structure control methods is that structural elements remain elastic during an earthquake. Since the magnitude of a future earthquake is not clear, this design is not economical and costeffective. As noted in the regulations, a structure should not be damaged considerably by a moderate earthquake and collapsed during a massive earthquake. However, prevention of collapse is no longer a criterion in modern buildings; during an earthquake, functional and non-structural elements of some structures are more valuable than the structures themselves and they need to be maintained during an earthquake. These structures include hospitals, police stations and nuclear plants. Seismic response and damage control will be improved by controlling energy applied to the structure and dissipating a major part of this energy by a mechanism independent of structural elements. As show in (1), an increase in $E_{d}$ reduces the energy applied to other parts of the structure. For this purpose, new techniques including energy absorption systems have been developed in engineering society [1].

$$
\mathrm{E}=\mathrm{E}_{\mathrm{k}}+\mathrm{E}_{\mathrm{s}}+\mathrm{E}_{\mathrm{h}}+\mathrm{E}_{\mathrm{d}}
$$

Where, $\mathrm{E}$ is the energy applied to the structure during an earthquake, $E_{k}$ denotes absolute kinetic energy, $E_{s}$ denotes elastic strain energy, $E_{h}$ denotes energy dissipated by the structural system itself and $E_{d}$ is the energy dissipated by energy absorption systems [2]. There are three types of energy dissipation systems including: 1) active and semi-active control systems; 2) passive control systems; and 3) hybrid control systems. In active control systems, some particular sensors are used in the building to determine changes in displacement, velocity and acceleration of the building. Using data analysis, a deterrent force is exerted by a stimulus in an opposite direction of the exerted force. In other words, active control systems tend to control behaviour of the building during an earthquake by exerting an external energy [3]. In passive control system, vibration-controlling element is well located in the structure; the control system which is passive before stimulation (earthquake) starts to control during stimulation and again becomes passive after earthquake. Many techniques are used in passive systems; these techniques include base isolators, viscoelastic dampers, metal dampers, tuned mass dampers and friction dampers. In a hybrid controlling system, both active and passive control systems are used simultaneously. Once stimulation begins, vibrations are reduced by the passive system; shortly after, the active system starts to operate. Then, the passive system may continue or stop working, if necessary [4]. This study examines the seismic behavior of a frame equipped with improved pall friction damper which is a passive system.

\section{MATERIALS AND METHODS}

As noted earlier, friction dampers are passive control systems. These dampers work based on friction mechanism between two rigid objects, one slipping over another. In fact, friction is a distinctive feature of energy dissipation. Previously, this idea has been used in automatic brakes (brake pads) of automobiles to dissipate kinetic energy. Currently, this technology is used to control a structure against earthquake. In general, friction tools well perform against earthquake and their response is independent of loading range, frequency and number of loading cycles [5]. Friction dampers are usually available in four types including: 1) Pall friction damper system; 2) Sumitomo friction damper system; 3) Gap-screw connection damper; and 4) rotational friction damper [3].

\section{A. Pall friction damper (PFD)}

A Pall damper is installed in the intersection of cross, chevron and single diagonal bracings [7]. This type of damper has been used in countries such as Canada, India, USA and China. Pall dampers have been approximately used in more 
than 90 buildings over the world; different types of Pall dampers have been suggested. A simple schematic can be found in [3]. A Pall damper consists of a series of steel plates made of special material which are interconnected by highresistance screws and well perform for friction. Pall dampers are widely used in cross bracings [8]. Hysteresis curves of several passive energy dissipation systems can be found in [1]. Energy absorption and dissipation is higher in the friction damper than in the other dampers due to the large area under the friction damper curve. It means that fewer devices are required for a certain level of earthquake; thus, it is costeffective [1].

Pall damper is considered better than other energy dissipation systems because 1) it is easy and cost-effective to build a Pall damper, 2) a Pall damper performs reliably against an earthquake, 3) energy dissipation is very high in a Pall damper due to its large hysteresis loop, 4) this damper performs independently from changes in velocity and temperature, 5) Pall dampers do not usually require considerable repair after the earthquake, 6) they can be hidden in blades, 7) due to rectangular hysteresis loop, these dampers are easily modelled in a computer [1]. In [8], authors introduced a new type of Pall damper which is used in cross bracings. These dampers are similar to PFDs, with a difference that their central core is Tshaped. This type of damper was called an Improved Pall Friction Damper (IPFD). A schematic can also be found in [7]. The mechanical performance of both dampers is entirely similar and they both absorb an equal amount of energy. Most of Pall's assumptions for PFD are true for IPFD. However, IPFD is considered better than PFD because 1) its configuration is easier, 2) its motor function is better, 3) its analysis is simpler, and 4) its construction costs lower.

\section{B. Optimum Slip Load}

The most important step in designing Pall systems (PFD and IPFD) is to determine optimum slip load of design. Structure response to vibrations is usually expressed by energy applied to the structure and energy dissipated by the structure. Accordingly, optimal vibration response occurs when there is minimal difference between energy applied to the structure and energy dissipated by the structure [9]. Slip load considered for Pall damper should fulfil following requirements [1]:

- Dampers should not slip during severe wind.

- Dampers should slip during a severe earthquake before yield of structural elements.

- Energy absorbed in the structure should be maximized by friction.

There are different methods used to determine optimum slip load; one of the most effective methods is non-linear timehistory analysis. In this method, a range of slip loads is selected based on existing standards; then, a series of non-linear dynamic analyses are done to determine slip load corresponding to minimum response as design slip load. Structural response may be based on items such as roof displacement, base shear, dissipated energy, etc.

\section{Damper Modeling in Computer}

Sap2000 was used to analyse the models [11]. There are generally two methods for modelling Pall damper; these methods include simple method and accurate method. The simple method was suggested by Pall; in this method, damper and bracings are replaced in the computer model only by simple bracing systems which yield under tension and pressure [10]. In this method, friction damper is modelled easily, because hysteresis loop of the friction damper is similar to rectangular loop of a full elasto-plastic material. Therefore, elastic bracings-friction dampers can be replaced by bracings which yield in slip load and damper slip load is considered as yield force of bracings [12]. In the second method suggestedin [9], all elements including bracings and damper links are defined by using linear elements and their stress-strain curve. This study used Pall's method for computer modelling.

\section{The Studied Frames}

The studied frame had 6 stories $(3 \mathrm{~m}$ in height) and 3 openings ( $4 \mathrm{~m}$ in width). Figure 1 shows a schema of this cross-braced frame. Loading of this frame was based on the sixth topic of national construction regulations according to which $0.8 \mathrm{Ton} / \mathrm{m}$ live load and $2.4 \mathrm{Ton} / \mathrm{m}$ dead load were applied to the stories. Since this study tended to compare dynamic behavior of frames, the frame with damper was considered similar to the frame without damper; only the damper was located in the structure. It is noteworthy that IPE and IPB profiles and double channel were used for columns, beams and bracings, respectively.

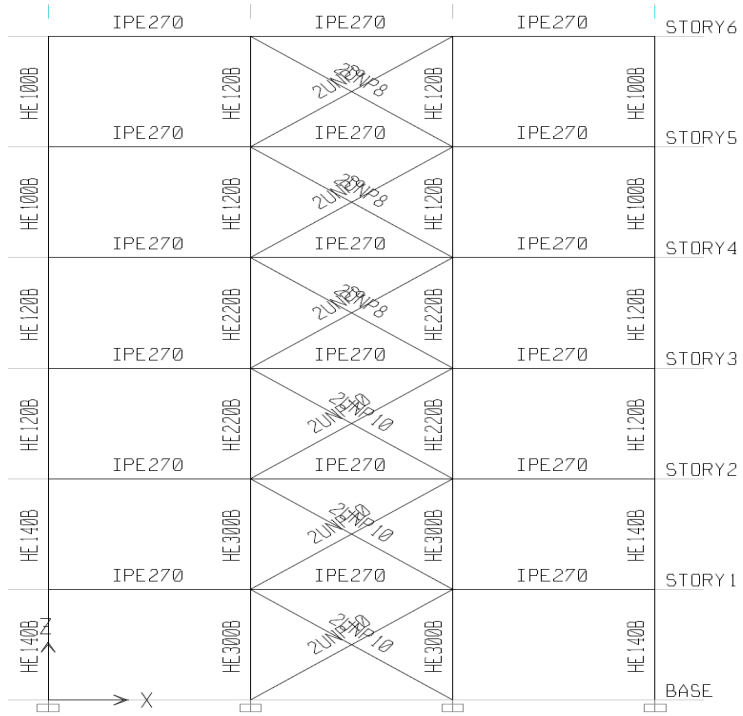

Fig. 1. The frame used in this study

\section{E. Selection and Scaling of Accelerograms Based on the 2800 Standard}

Four accelerograms of Kobe, Naghan, Tabas and Sanfernando earthquakes were used for dynamic time-history analysis of frames. The accelerograms were modified and 
scaled based on the Iran seismic code (the Standard 2800) [13]. Figures 1 and Figure 2 show the scaling procedure.

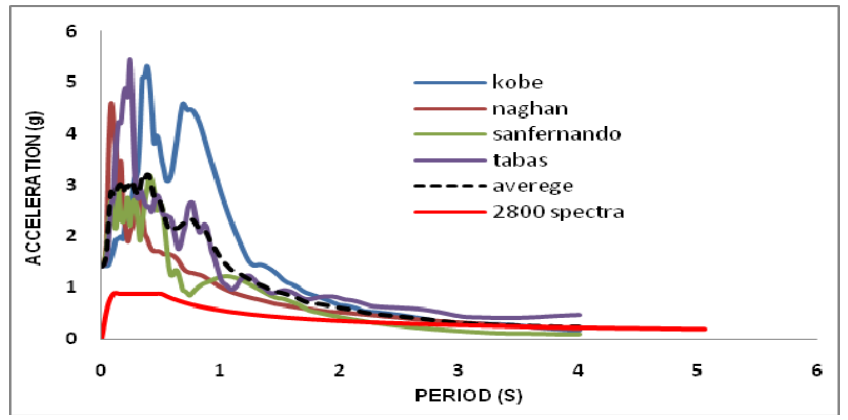

Fig. 2. Mean acceleration spectrum

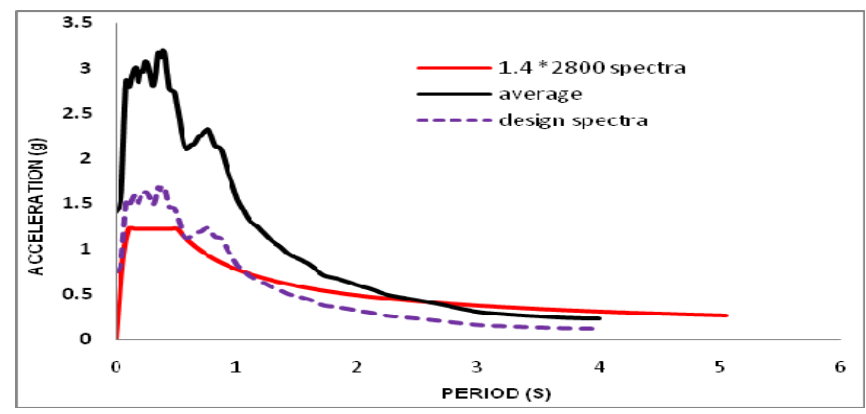

Fig. 3. Scale of accelerograms and design spectrum

Then, 53\% scale factor was selected for two 6-story structures with and without dampers. This factor is given to the application.

\section{F. Selection of Optimum Slip load for Dampers}

The frame with friction damper was exposed to different accelerograms. Roof displacement was plotted versus different slip loads. As shown in Figure 4, the structure under 12-ton slip-load had the lowest response (lowest displacement) in all accelerograms. Thus, optimum slim-load was 12 ton.

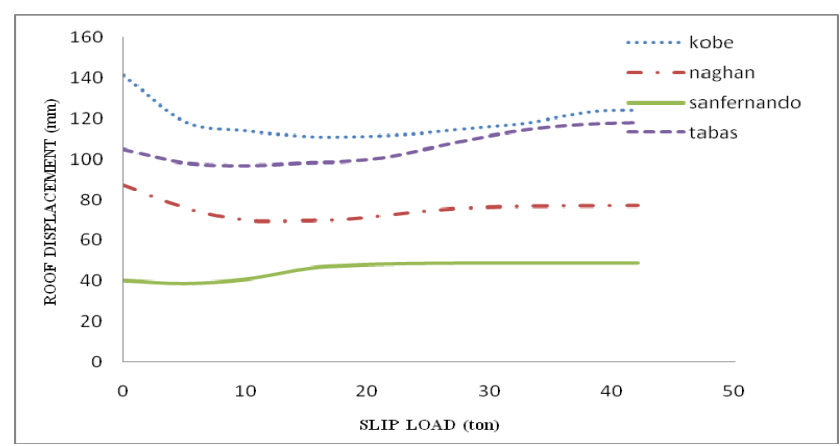

Fig. 4. Roof displacement under different accelerograms versus different slip loads

\section{RESULT}

A. Time-history Non-linear Analysis of Cross-braced Frames In this section, the cross-braced frame was modelled in Sap2000 and exposed to non-linear dynamic analysis under Tabas, Naghan, Kobe and Sanfernando earthquakes with 53\% scale factor. Some results are shown in Figures 5 and 6. These results include maximum roof displacement and base shear.

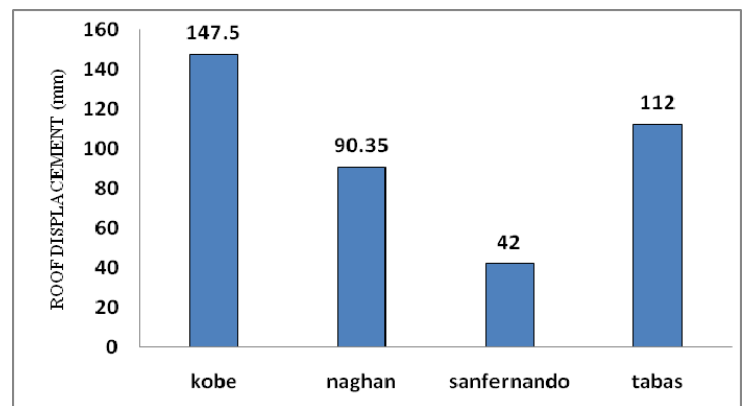

Fig. 5. Maximum roof displacement

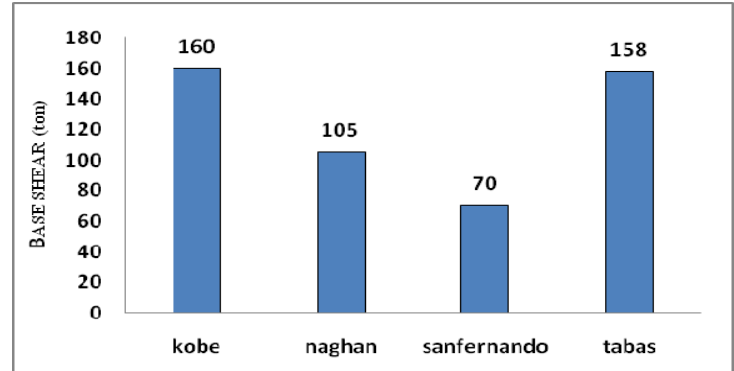

Fig. 6. Maximum base shear

B. Time-history Non-linear Analysis of Frames with IPFD

\section{Damper}

The frame with IPFD damper was modelled in Sap2000 and exposed to Tabas, Naghan, Kobe and Sanfernando earthquakes with 53\% scale factor and 12-ton damper slip-load. Figures 7 to 10 show the results of analysis including maximum base shear, maximum roof displacement, damper hysteresis diagram and energy absorbed by the dampers.

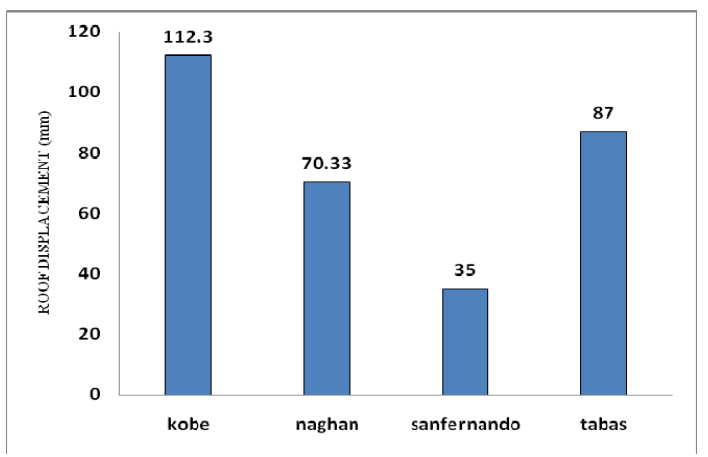

Fig. 7. Maximum roof displacement 


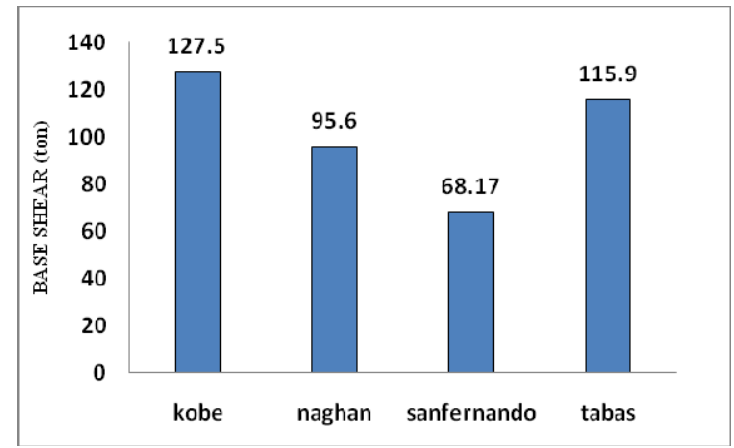

Fig. 8. Maximum base shear

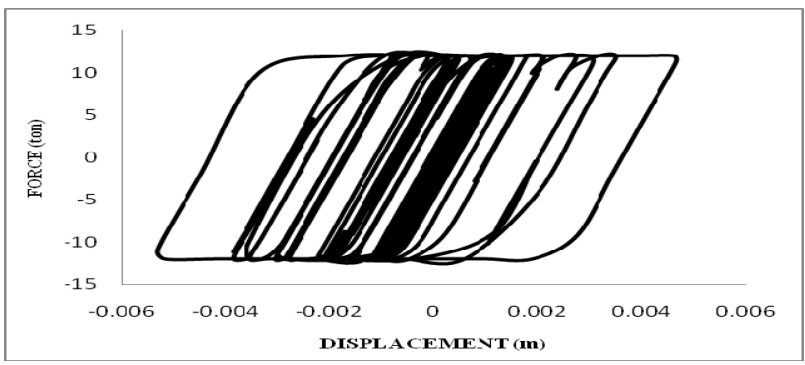

Fig. 9. Hysteric behavior of IPFD under Tabas earthquake

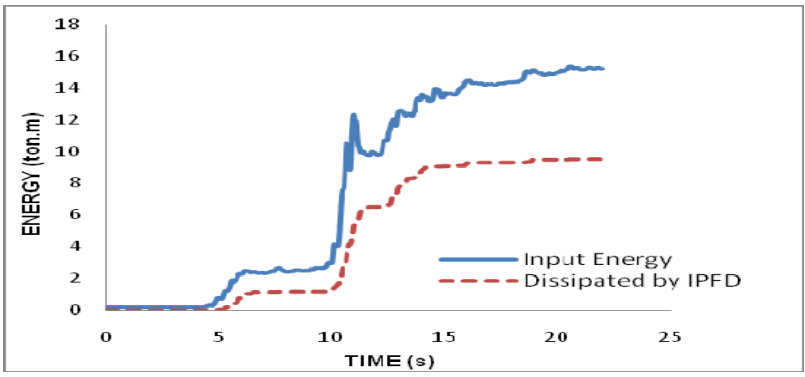

Fig. 10. Input energy and energy absorbed by IPFD under Tabas earthquake

\section{Analysis of Results}

Figures 11 and 12 compare base shear and maximum roof displacement in two frames with and without dampers.

\section{CONCLUSION}

This study compared the performance of steel frames with concentric steel bracing reinforced by IPFD and steel frames with concentric steel bracing with no damper. Frames with different stories and pans were modelled in sap2000 and exposed to accelerograms of earthquakes for non-linear time history analysis. Final conclusions are achieved as follows:

- IPFD significantly reduces base shear in the frame.

- IPFD reduces total and relative displacement in stories.

- Damper outperforms in severe earthquakes such as Kobe and Tabas earthquakes.
- Dampers dissipate a great deal of energy; in absence of dampers, this energy damages other parts of the structure.

- In a structure, energy dissipated by a damper varies considering its location in the structure and the load applied to it during an earthquake.

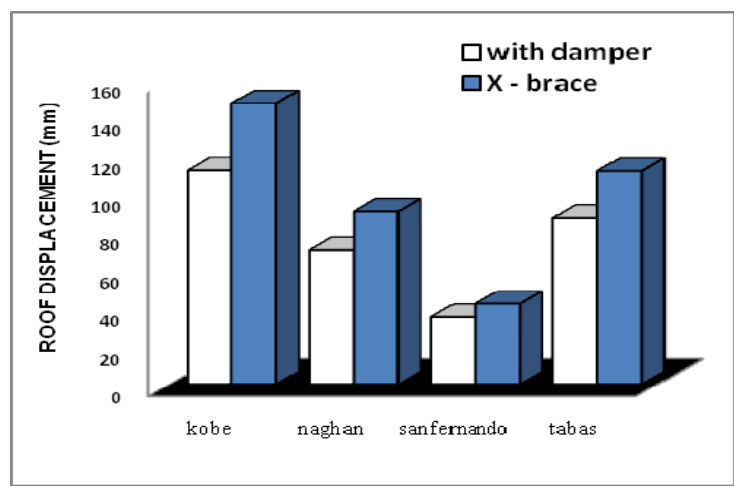

Fig. 11. Comparison of roof displacement in frames

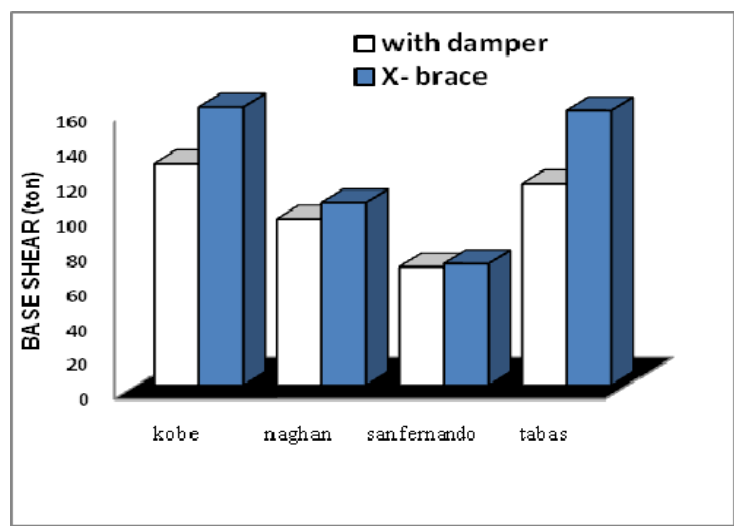

Fig. 12. Comparison of base shear in frames

\section{REFERENCES}

[1] A. Pall, "Performance-based design using pall friction dampers-an economical design solution", 13th World Conference on Earthquake Engineering, Vancouver, BC, Canada, 2004

[2] M. C. Constantinou, "Principles of Friction, Viscoelastic., Yielding Steel and Fluid Viscous DAMPERS: Properties and Design", In Passive and Active Structural Vibration Control in Civil Engineering, Springer Vienna, 1994.

[3] V. Ruiz, K. Walsh, M. M. Abdullah, Investigating The Energy Dissipating Properties of Passive Friction Devices, Florida State University, Tallahassee, Florida; Tokyo Institute of Technology, Tokyo, Japan, 2005

[4] J. Marko, D. Thambiratnam, N. Perera, "Influence of damping systems on building structures subject to seismic effects", Engineering Structures, Vol. 26, No. 13, pp. 1939-1956, 2004

[5] L. Di Sarno, A. S. Elnashai, "Seismic retrofitting of steel and composite building structure",. Mid-America Earthquake Center CD Release 02-01, 2002

[6] M. C. Constantinou, M. D. Symans, Experimental and analytical investigation of seismic response of structures with supplemental fluid 
viscous dampers, Buffalo, NY: National Center for Earthquake Engineering Research, 1992

[7] . F. F. Miguel, R. H. Lopez, "Simultaneous optimization of force and placement of friction dampers under seismic loading", Engineering Optimization, Vol. 48, No. 4, pp. 582-602, 2016

[8] B. Wu, J. Zhang, M. S. Williams, J. Ou, "Hysteretic behavior of improved Pall-typed frictional dampers", Engineering Structures, Vol. 27, No. 8, pp. 1258-1267, 2005

[9] A. S. Pall, C. Marsh, "Response of friction damped braced frames", Journal of Structural Engineering, Vol. 108, No. 9, pp. 1313-1323, 1982

[10] A. Filiatrault, S. Cherry, "Comparative performance of friction damped systems and base isolation systems for earthquake retrofit and aseismic design”, Earthquake Engineering \& Structural Dynamics, Vol. 16, No. 3, pp. 389-416, 1988

[11] A. Ravitheja, "Seismic Evaluation of Multi Storey RC Buildings with and without Fluid viscous dampers", Global Journal of Research In Engineering, Vol. 16, No. 1, pp. 10-15, 2016

[12] S. K. Lee, J. H. Park, B. W. Moon, K. W. Min, S. H. Lee, J. Kim, "Design of a bracing-friction damper system for seismic retrofitting", Smart Structures and Systems, Vol. 4, No. 5, pp. 685-696, 2008

[13] L. H. Najafi, M. Tehranizadeh, "Ground motion selection and scaling in practice”, Periodica Polytechnica, Civil Engineering, Vol. 59, No. 2, pp. $232-233,2015$ 